\title{
Dispositivos de Integração da Rede Assistencial em Saúde Mental: a experiência do Serviço de Saúde Dr. Cândido Ferreira
}

\section{Integration Devices of the Mental Health Care Network: the experience of Serviço de Saúde Dr. Cândido Ferreira}

\section{Gustavo Zambenedetti}

Psicólogo. Mestre em Psicologia Social e Institucional.

Endereço: Rua Santana, 575, ap. 406, Bairro Santana, CEP $90040^{-}$

373, Porto Alegre, RS, Brasil.

E-mail: gugazamळterra.com.br

\section{Resumo}

O objetivo deste artigo é tecer uma discussão sobre dispositivos de integração de uma rede assistencial em saúde mental, tendo em vista a experiência desenvolvida no Serviço de Saúde Dr. Cândido Ferreira (SSCF), localizado no município de Campinas-SP. Apresenta o modo como o tema da integração da rede assistencial configura-se como ponto de discussão no contexto da Reforma Psiquiátrica brasileira e institucionalização do Sistema Único de Saúde (SUS). Aborda a importância da implementação de uma rede de serviços inter e intrassetorial, acompanhada por uma mudança nos processos de trabalho, em especial com a inserção de equipes e profissionais de referência, visando garantir manutenção de vínculos e continuidade da assistência nos diferentes níveis assistenciais. Problematiza a relação entre os planos macro e micropolíticos, assim como a necessidade de criação de dispositivos de integração de rede assistencial que complementem o mecanismo de referência e contrarreferência, tradicionalmente preconizado no âmbito do SUS.

Palavras-chave: Rede assistencial; Reforma psiquiátrica; SUS; Dispositivos. 


\section{Abstract}

The aim of this article is to discuss the integration devices of a mental health care network, in light of the experience developed at Serviço de Saúde (Health Service) Dr. Cândido Ferreira (SSCF), situated in Campinas, state of São Paulo. The article presents the way in which the theme of the health network integration is configured as a point of discussion in the context of the Brazilian Psychiatric Reform and of the institutionalization of Sistema Único de Saúde (SUS - National Health System). The article approaches the relevance of the implementation of an inter- and intra-sectoral services network, together with a change in the work processes, especially with the insertion of referral teams and professionals, aiming to guarantee the maintenance of bonds and the continuity of assistance in different assistance levels. The relation between the macro- and micro-political levels is discussed, as well as the need to create devices to integrate the assistance network; such devices should complement the referral and counter-referral mechanism that is traditionally professed by SUS.

Keywords: Assistance Network; Psychiatric Reform; SUS; Devices.

\section{Introdução}

A partir do contexto da Reforma Psiquiátrica brasileira da segunda metade da década de 1980, constitui-se como bandeira do movimento da luta antimanicomial a extinção dos hospitais psiquiátricos e sua progressiva substituição por uma rede de atenção em saúde mental. Essa rede seria composta de uma série de serviços e ações, como Centros ou Núcleos de Atenção Psicossocial, Serviços Residenciais Terapêuticos, leitos em hospitais gerais, centros de convivência, ações de saúde mental na Estratégia de Saúde da Família (ESF), entre outros. Vários municípios brasileiros vêm desenvolvendo esse processo, marcadamente a partir da década de 1990. Segundo Lancetti (2006), SantosSP foi o primeiro município brasileiro a substituir completamente o hospital psiquiátrico por uma rede territorial de cuidados em saúde mental, em 1993.

É necessário ressaltar que o processo de substituição do hospital psiquiátrico por uma rede de atenção em saúde mental envolve muito mais do que o simples deslocamento dos espaços de cuidado, envolvendo uma complexa mudança de paradigmas e de práticas no campo da saúde mental. Segundo Amarante (1996), baseado na perspectiva da desinstitucionalização italiana, trata-se de uma mudança do paradigma problema-solução/doença-cura para o paradigma da complexidade, em que o objeto deixa de ser a doença mental e passa a ser o sujeito em sofrimento em relação ao corpo social. A gênese do hospital psiquiátrico insere-se dentro da primeira lógica, enquanto a rede de atenção dentro da segunda lógica. A necessidade de uma atenção em rede emerge justamente porque o hospital psiquiátrico e as práticas nele agenciadas deixam de ser suficientes para dar conta das demandas engendradas no processo de produção de saúde, as quais envolvem articulações tanto intrassetoriais - serviços e ações de saúde dos diferentes níveis de atenção - quanto intersetoriais - moradia, trabalho, cultura.

Vários desafios, porém, têm sido impostos à implementação das redes de atenção em saúde mental. Esse artigo focaliza um desafio em especial: a constituição de uma rede realmente articulada de serviços e ações de saúde mental. Apesar da criação de diferentes modalidades de serviços e de seu processo de gradual implementação, ainda não podemos dizer que de fato os municípios têm conseguido constituir uma rede integrada de serviços e ações em saúde mental. 
devemos nos perguntar sobre a existência da rede, pois o que temos vivido, grande parte das vezes, é uma falta de portas de saída. Os pacientes chegam, são atendidos e ficam. Os pacientes chegam, são atendidos e não se tem para onde encaminhá-los. Aqui, é a noção de rede que deve ser arguida, pois se entendemos serem características principais de uma rede sua acentralidade, sua conectividade e sua conexão permanente, o que temos visto funcionar é menos uma rede e mais um conjunto de pontos ligados frágil e burocraticamente (Barros, 2003, p. 205).

O que foi apontado por Barros (2003) já vinha sendo constatado na realidade local do município de Santa Maria-RS, a partir da vivência cotidiana em serviços de saúde do SUS e dos contatos estabelecidos com gestores e trabalhadores em pesquisas, práticas de estágio e participação no controle social (Zambenedetti e Perrone, 2008). As dificuldades encontradas na constituição de uma rede local articulada de serviços e ações em saúde mental levaram à busca de conhecimento de outras experiências consideradas exitosas de constituição de redes de atenção em saúde mental. Deve-se esclarecer que, nessa busca, não se trata de estabelecer modelos. Apoiando-se em Campos (2000), utiliza-se a ideia de "modelagens" da reforma psiquiátrica, que diz respeito a como um modelo foi apropriado e recriado, desenhando contornos singulares. Modelagem:

é o desenho que formata toda experiência, que tem como pano de fundo um modelo que já foi experimentado. Assim sendo, MODELAGEM passa a ser: fazer saúde num determinado local, com uma determinada história de inserção de serviços de saúde e em um determinado tempo histórico com seus protagonistas singulares (Campos, 2000, p. 67).

Nesse sentido, buscou-se conhecer a experiência desenvolvida pelo Serviço de Saúde Dr. Cândido Ferreira (SSCF), no município de Campinas-SP, considerado referência em saúde mental pela Organização Mundial da Saúde desde 1993. A partir dessa experiência buscou-se pensar novas ferramentas de trabalho que pudessem operar na realidade cotidiana, oferecendo novas possibilidades de construção de soluções no campo da saúde mental.

\section{Procedimentos}

Com a finalidade de conhecer a experiência desenvolvida no SSCF, localizado no município de Campinas-SP, foi firmado um convênio entre o curso de Psicologia da Universidade Federal de Santa Maria (UFSM) e o Serviço de Saúde Dr. Cândido Ferreira (SSCF), que possibilitou um intercâmbio caracterizado por dois momentos. Inicialmente, duas profissionais do SSCF foram até Santa Maria-RS e estabeleceram espaços de discussão com alunos de graduação da UFSM, gestores e trabalhadores vinculados à Secretaria da Saúde do Município de Santa Maria-RS. Nessas discussões, foi possível conhecer o trabalho desenvolvido no SSCF, assim como abordar os atuais desafios da Reforma Psiquiátrica no município de Campinas e de Santa Maria. Num segundo momento, seis alunos do curso de graduação em Psicologia da UFSM realizaram estágio em diferentes serviços de saúde mental vinculados ao SSCF, durante o período de um mês (fevereiro/2005). Na primeira semana, os alunos conheceram os diferentes serviços que compõem a rede assistencial vinculada ao SSCF. Nas duas semanas seguintes, cada aluno foi inserido em um diferente serviço: CAPS III Estação, CAPS III Esperança, CAPS III Toninho, Núcleo Clínico, Núcleo de Atenção a Dependência Química (NADEQ), Núcleo de Atenção a Crise (NAC) e Núcleo de Oficinas de Trabalho (NOT). Cada serviço designou um técnico de referência, responsável por agenciar a participação do aluno nas ações em saúde e supervisionar suas atividades locais. Houve ainda supervisões coletivas com um representante do SSCF, nas quais foi possível problematizar as vivências cotidianas ${ }^{1}$.

Os dados trabalhados neste artigo resultam do diário de pesquisa do autor deste artigo e participante do estágio, realizado no mês de fevereiro de 2005. Além de conhecer a rede de serviços vinculados ao SSCF, o autor permaneceu inserido durante duas semanas no CAPS III Estação, cumprindo cerca de oitenta horas de observação-participante. Nesse período, foi possível acompanhar as atividades desenvolvidas nesse serviço e investigar as tecnologias que podem servir como dispositivos de integração entre os serviços que compõem a rede assistencial. Para o registro dos dados, procedeu-se a elaboração de um diário de pesquisa, em

\footnotetext{
1 Em Merhy e Amaral (2007) é possível encontrar um maior detalhamento do processo de construção dessa experiência de estágio extracurricular.
} 
que foi possível registrar o conteúdo das conversas diárias, as observações, impressões, discussões com os demais estagiários e supervisores.

Uma das perguntas que guiou tanto a observação quanto a seleção dos dados para a escrita desse artigo foi "como ocorre a articulação da rede de serviços e ações em saúde mental a partir do SSCF no município de Campinas-SP?"

Dessa maneira, inicialmente situa-se o campo de observação. Em seguida, descrevem-se as principais características da organização dos serviços e ações da rede vinculada ao SSCF, assim como características da organização do processo de trabalho nas equipes de saúde. Em um terceiro tópico são apresentados três recortes considerados paradigmáticos por apresentarem novas possibilidades de constituição de dispositivos de integração da rede assistencial.

É necessário ressaltar que os dados trabalhados neste artigo representam um recorte temporal, tendo em vista que a observação ocorreu em fevereiro de 2005. Sendo a Reforma Psiquiátrica um processo, certamente muitas mudanças devem ter ocorrido nos modos de operar a rede assistencial em saúde mental dessa data até o momento de publicação deste artigo. Porém, ao propor uma análise tendo como base os dados encontrados nas observações, trabalha-se com a ideia de constituição de um "diagrama impossível", tal qual proposto por Latour (2001). Segundo o autor, a cartografia de um processo é sempre provisória. A investigação de um objeto processual, que se transforma ao longo do tempo (como é o caso do processo de constituição das redes de atenção em saúde mental), envolve a efetivação de um recorte espaço-temporal em relação ao campo de observação. Isso não significa que o processo não continue evoluindo no tempo, ou que se tenha conseguido capturar exaustivamente todas as linhas que o constituem. Significa que foi constituído um diagrama que possui características de mobilidade, transformação, rearranjo. Apesar da impossibilidade de constituir um diagrama que revele uma forma definitiva, Latour (2001) coloca a necessidade de as cartografias serem realizadas, considerando que elas revelam arranjos temporários, situados no tempo e no espaço. É dentro dessa perspectiva que trabalharemos os dados apresentados neste artigo.

\section{Apresentação dos Dados}

\section{Campinas-SP: a experiência do SSCF}

As obras A reforma psiquiátrica no cotidiano (Harari e Valentini, 2001) e A reforma psiquiátrica no cotidiano II (Merhy e Amaral, 2007) constituem-se em referências sobre a experiência desenvolvida pelo Serviço de Saúde Dr. Cândido Ferreira (SSCF)². Dessa maneira, não cabe aqui reconstituir toda a história da reforma psiquiátrica em Campinas, cabendo apenas mencionar resumidamente alguns pontos para situar o leitor. 0 "Sanatório Dr. Cândido Ferreira" foi fundado em 1924, no Distrito de Sousas, em Campinas-SP. Funcionou como manicômio até 1990, reproduzindo a lógica manicomial perpassada pela cronificação e institucionalização da clientela. Em 1990 foi estabelecido um convênio de co-gestão entre o Sanatório Dr. Cândido Ferreira e a prefeitura de Campinas. Esse convênio teve uma série de repercussões no campo da gestão e da assistência em saúde mental, sendo um importante disparador do processo de reforma psiquiátrica. As contratações profissionais via seleção pública propiciaram a seleção de profissionais com perfil caracterizado pela formação antimanicomial e identificação com esse princípio. No plano assistencial o processo de mudança teve início no serviço de internação de agudos. Houve contratação de novos profissionais, composição de equipe multidisciplinar, estabelecimento de diretrizes voltadas à desintitucionalização, tensionando a emergência de novas formas de olhar e cuidar o sujeito em sofrimento psíquico (Harari e Valentini, 2001). A partir dessa instituição filantrópica - que muda o nome da instituição para "Serviço de Saúde Dr. Cândido Ferreira" - passou a ocorrer a implantação de uma série de outros serviços, visando substituir a lógica hospitalocêntrica pela lógica da rede de cuidados territoriais. No início da década de 1990, constituiu-se um hospital-dia, visando oferecer atenção diária fora da instituição hospitalar. Começaram também as primeiras experiências de moradias protegidas, com a finalidade de desinstitucionalizar os moradores do hospício ${ }^{3}$. Essas mudanças graduais no sistema de assistência em saúde mental ocorreram ao longo da década de 1990 e anos 2000. A partir dos anos 2000 passou a ocorrer uma

\footnotetext{
2 Para ampliar a leitura, indicamos os autores Onocko e Amaral (1997) e Campos (2000).

3 Ressalta-se o protagonismo institucional, pois tanto o hospital-dia quanto as pensões protegidas foram implantadas antes que houvesse uma portaria nacional que regulamentasse e dispusesse sobre seu financiamento.
} 
ênfase na implantação de CAPS, sendo que em 2005 existiam 3 CAPS III vinculados ao SSCF, distribuídos em diferentes regiões de Campinas-SP. Em fevereiro de 2005 , período no qual conhecemos a experiência do SSCF, a rede de serviços vinculados ao SSCF contava com: Núcleo de Atenção à Crise (NAC), destinado à internação de usuários psicóticos/neuróticos graves em situação de crise; Núcleo de Atenção à Dependência Química (NADEQ), destinado à internação de usuários de álcool e outras drogas; Núcleo Clínico, que se constitui numa unidade de moradores institucionalizados que necessitam de cuidados clínicos especiais; Casa Primavera, unidade de moradia ${ }^{4}$; Serviços Residenciais Terapêuticos (mais de 30 unidades implantadas em diferentes bairros de Campinas); CAPS III Estação; CAPS III Esperança; CAPS III Toninho; Núcleo de Oficinas de Trabalho (NOT), com atividades de trabalho e geração de renda para usuários com sofrimento psíquico (nas seguintes áreas: mosaico, reciclagem de papel, vitral e vitral plano, vela, gráfica, marcenaria, cozinha, horta, construção); à este núcleo articulase um bar, um restaurante e uma loja localizadas no distrito de Sousas, além de uma loja-café situada em um bairro central em Campinas - onde os usuários da saúde mental trabalham e comercializam os produtos confeccionados nas oficinas ${ }^{5}$. Esta estrutura está em permanente mudança, desencadeada a partir das avaliações realizadas pelas equipes de saúde mental. Mas desde já se evidencia a diversificação dos serviços e ações em saúde mental, assim como as interfaces do campo da saúde mental com os campos do trabalho protegido, moradia e cultura.

\section{Serviços, Equipes e Profıssionais de Referência: o pro- cesso de referenciamento de usuários entre serviços}

Os CAPS vinculados ao SSCF são distribuídos por regiões geográficas do município de Campinas: o CAPS III ${ }^{6}$ Toninho (região Sul), CAPS III Esperança (região Leste) e o CAPS III Estação (região Norte). As demais regiões são cobertas pelos dois CAPS vinculados à Secretaria de Saúde do Município de Campinas. Todos os CAPS assumem a função de referência em relação à atenção básica e aos Serviços Residenciais Terapêuticos de suas respectivas regiões.

Dentro do CAPS III Estação existem quatro equipes multiprofissionais de referência (compostas predominantemente de psiquiatras, psicólogos, terapeutas ocupacionais, enfermeiros). Uma dessas equipes é referência apenas para os Serviços Residenciais Terapêuticos, enquanto as outras três são referências para a atenção básica. Cada equipe é responsável por um número de usuários (que varia em média entre 50 e 70), e cada profissional é técnico de referência para um grupo de usuários. Dessa maneira, o usuário estará sempre vinculado ao CAPS; a uma equipe de referência do CAPS; a um técnico de referência do CAPS. 0 técnico de referência juntamente com a equipe de referência são responsáveis pela elaboração do Projeto Terapêutico Individual (PTI) do usuário.

A mesma lógica de constituição de equipes de referência presente no CAPS também está presente na atenção básica de Campinas. Os Centros de Saúde são compostos de equipes, também responsáveis pelos usuários de uma área adscrita. Dessa forma, quando um Centro de Saúde faz um encaminhamento para o CAPS, fará preferencialmente para a mesma equipe. Da mesma forma, quando o CAPS precisar entrar em contato com a atenção básica, seguirá a lógica de relação baseada na adscrição de áreas e delimitação de referências entre uma equipe do CAPS e uma equipe dos Centros de Saúde. Esse sistema possibilita a corresponsabilização, delimitando claramente quem deve desempenhar as atividades, assim como a criação de vínculos entre usuários-profissionais e profissionais do CAPS-profissionais da atenção básica. A referência deixa de ser apenas a "instituição Centro de Saúde" ou a "instituição CAPS" e passa a ser o profissional e a equipe de referência.

Preconiza-se, ainda, que o encaminhamento para o CAPS seja precedido pela discussão do caso, em que seja possível o estabelecimento de uma parceria entre o CAPS e o Centro de Saúde, em vez de uma transfe-

\footnotetext{
4 Esses moradores têm sido gradualmente transferidos para Serviços Residenciais Terapêuticos, de maneira que tanto o Núcleo Clínico quanto a Casa Primavera tendem a ser extintos.

5 Apesar de nossa experiência ter se constituído a partir dessa rede de serviços vinculados ao SSCF, é necessário considerar que existem outros serviços de saúde mental em Campinas vinculados diretamente à Secretaria de Saúde do Município e a PUCCAMP.

6 O CAPS III é uma modalidade de CAPS com funcionamento 24h, durante sete dias da semana, com leitos para eventual repouso e/ou observação. Pode ser implantado em municípios com população superior a 200.000 habitantes (Brasil, 2004).
} 
rência de responsabilidade. Porém, essa é apenas uma diretriz da macropolítica, nem sempre se atualizando exatamente tal qual é proposta. Segundo o relato de um profissional do CAPS III Estação, a aproximação com alguns Centros de Saúde ocorre com mais facilidade do que com outros, dependendo da identificação do profissional da atenção básica com questões relacionadas à saúde mental e da presença de equipes de saúde mental na atenção básica. Também foi apontado o fato de que nem sempre o profissional de referência assume de fato seu papel, sendo necessário o contato com outro profissional mais "sensível" às questões de saúde mental. Em última instância, a atualização das diretrizes macropolíticas da rede de saúde mental inclui um fator subjetivo, relacionado à implicação do trabalhador com as diretrizes do processo de trabalho. Isso demonstra o alto grau de autonomia que tradicionalmente caracteriza o trabalho em saúde, aspecto apontado por Merhy (2002). O trabalhador não apenas executa ações de acordo com as normas e diretrizes dos serviços, incorporando também sua subjetividade, suas crenças, medos e desejos nas atividades desenvolvidas. Aponta-se, então, a constituição de um desafio: a aproximação entre os objetivos colocados no âmbito do Sistema Único de Saúde e da Reforma Psiquiátrica com os processos de subjetivação dos trabalhadores no campo da saúde.

\section{Generalidades e singularidades}

Durante uma supervisão, discutiu-se se os demais CAPS vinculados ao SSCF também organizavam seus processos de trabalho como o CAPS III Estação. Segundo foi relatado por uma profissional do SSCF, existe uma organização que é comum a todos os CAPS vinculados ao SSCF: cada CAPS é referência para uma região; os trabalhadores são dispostos em equipes de referência multiprofissionais; cada uma dessas equipes é referência para alguns Centros de Saúde. Observa-se que esses elementos conformam a macropolítica do funcionamento da rede de saúde mental vinculada ao SSCF e aos demais serviços de saúde do SUS em Campinas. Macropolítica entendida a partir de sua determinação por instâncias normativas, envolvendo modelos e métodos organizacionais. Nesse plano, a operacionalização das equipes e profissionais de referência pode servir como dispositivo ${ }^{7}$ de articulação entre os serviços, possibilitando uma clara delimitação de responsabilidades e fluxos de comunicação e pessoas entre os serviços.

Porém, de um CAPS para outro existem algumas variações, como, por exemplo, na forma da composição das equipes. No CAPS III Estação, um dos critérios de composição das equipes de referência foi a heterogeneidade teórica entre os profissionais. Mas esse critério é uma singularidade desse CAPS, não sendo uma regra instituída na política de Saúde Mental de Campinas ou do SSCF. Outra singularidade desse CAPS é o fato de que os psiquiatras são considerados "profissionais transversais", que circulam pelas diferentes equipes dentro do CAPS. A constituição de uma equipe específica para referenciar os Serviços Residenciais Terapêuticos (SRT) também foi uma decisão construída na equipe, alterando o processo de trabalho e o modo de produzir a atenção aos moradores dos SRTs.

Nesse sentido, as definições macropolíticas servem como diretrizes da organização dos processos de trabalho, mas são constantemente colocadas em análise a partir da experiência micropolítica dos processos de trabalho, em ato (Merhy, 2002), sendo passíveis de mudanças e reorganizações. Muitas falas de profissionais expressavam o importante papel desempenhado pela supervisão institucional e pelas reuniões de equipe e de equipes de referência. Essas reuniões eram vislumbradas como dispositivos de análise dos processos de trabalho, possibilitando a explicitação de problemas e a formulação de estratégias de mudança.

Nesse sentido, deve-se apontar que tão importante quanto apresentar as tecnologias que operaram como dispositivos de integração da rede assistencial no plano macropolítico é apontar a existência de um processo de avaliação constante das ações desenvolvidas no plano micropolítico. Esse processo de avaliação constante propicia a reformulação das diretrizes estabelecidas. Nesse ponto temos uma articulação entre a macro e a micropolítica, pois o processo de avaliação constante permite que as diretrizes macropolíticas não se institucionalizem ${ }^{8}$.

7 Entende-se a noção de dispositivo tal qual foi proposta por Foucault (2006): conjunto heterogêneo de elementos (discursos, medidas administrativas, enunciados científicos, filosóficos) que faz algo funcionar, dispara processos, designando uma função estratégica. 0 dispositivo nunca pode ser visto como um objeto isoladamente, mas sim em relação às conexões que estabelece.

8 Institucionalização entendida como burocratização, cristalização. 


\section{A Relação PSF - CAPS e NAC - CAPS: compartilhando responsabilidades}

A seguir destacam-se três situações consideradas paradigmáticas por indicarem mudanças implementadas com o novo modelo de assistência em saúde mental preconizado pela modelagem construída pelo SSCF. Essas situações nos fazem pensar em outros dispositivos de integração entre os serviços, fugindo do mecanismo de "referência" e "contrarreferência" tradicionalmente preconizado no âmbito da saúde pública9

Terça-feira, 8h-1oh: realização de supervisão clínica. Nessa reunião, realizada no CAPS III Estação, estavam presentes: toda a equipe do CAPS, três técnicos de um Centro de Saúde (médico generalista, coordenadora do Centro de Saúde e agente comunitária de saúde), supervisor clínico. 0 principal assunto da supervisão foi a discussão de um caso considerado bastante complexo, requerendo ações compartilhadas entre o CAPS e o Centro de Saúde. Inicialmente tinha-se como demanda a necessidade de atenção a um homem que apresentava sintomas psicóticos. Houve a realização de visitas domiciliares pelas equipes do CAPS e do Centro de Saúde. Nessas visitas, observou-se uma família composta de mãe e três filhos, todos adultos-jovens. A partir dos contatos com a família observou-se que todos tinham algum tipo de problema: os três irmãos apresentavam sintomas psicóticos, a mãe apresentava sinais de demência, sendo necessária a realização de exames que confirmassem o diagnóstico e direcionassem seu tratamento. Essa situação tornou o caso mais complexo, pois parecia difícil encontrar alguém na família que pudesse apoiar o outro. Discutiram-se estratégias de construção de uma rede apoio/assistência, formas de “organizar" a moradia, necessidade de tratamento da mãe, tentativa de elaboração de um contrato de responsabilização entre a instituição e a família. Foi explicitado que a política do SSCF é optar pela alternativa menos invasiva. Nesse sentido, tentase apostar na capacidade de alguém da família (outros parentes, rede social) se sensibilizar com a situação da mãe e dos irmãos antes de se proceder a intervenções institucionais que possam levar a institucionalização. Ao final, delinearam-se os procedimentos a serem realizados, o que seria responsabilidade de cada profissional e serviços (Diário de Pesquisa).

Situação de reunião entre a equipe do NAC e do CAPS para discussão de caso de usuário que é referenciado pelo CAPS e está internado no NAC:

A tarde houve reunião da miniequipe do CAPS (composta de médico, psicólogo, enfermeira e terapeuta ocupacional) com profissionais de uma miniequipe do NAC (terapeuta ocupacional, enfermeira e estagiária) e com familiar do usuário sobre o qual seria discutido o caso. 0 usuário em questão está internado no NAC, mas lúcido e com condição de alta. Porém, com problemas clínicos - câncer em estado avançado, com possível metástase. Ele tem uma casa em região periférica da cidade e antes de ser internado morava sozinho. Porém, a casa já foi apedrejada e invadida, estando ocupada por invasores. Em função dessas circunstâncias e da necessidade de cuidados imediatos, os profissionais tentaram negociar com a irmã do usuário algumas alternativas, entre as quais estariam: ir para um dos quartos na casa da irmã, o qual teria que passar por algumas pequenas reformas para ser adaptado, ir para uma pensão, ser transferido para um leito hospitalar, pagar uma pessoa para cuidar dele com um dos auxílios que ele recebe (em qualquer um dos lugares que ficasse). Discutiram-se ainda possibilidades de reaproximação com outro irmão, a fim de evitar uma sobrecarga de uma das irmãs. Também se discutiu o que poderia ser feito em relação à casa invadida. Ao final, a irmã do usuário disse que pensaria melhor nas possibilidades discutidas, e então eles se encontrariam novamente para tomar as providências necessárias (Diário de Pesquisa).

Nas duas situações relatadas, destacam-se a ação e o planejamento conjuntos entre equipes de diferentes

9 Muitas vezes visto sob uma perspectiva burocrática, o mecanismo de referência e contrarreferência enfatiza o deslocamento do usuário de um serviço a outro, envolvendo transferência de responsabilidade de um serviço a outro. Tem como objetivo propiciar acesso a outros níveis de atenção e complexidades. Mas existe o risco de se transformar em simples "empurroterapia”, que faz com que o usuário tenha que percorrer vários serviços em busca da resolução da seus problemas. 
serviços, envolvendo ainda a família do usuário. Além de esse sistema propiciar a manutenção de vínculos da equipe com os usuários, também ocorre criação e manutenção de vínculos entre as equipes dos diferentes serviços, facilitando a comunicação e a troca de informações entre eles. Essas situações apontam que a circulação das equipes pelos serviços e o planejamento/ execução de ações conjuntas entre diferentes equipes podem constituir-se em dispositivos de articulação da rede assistencial. Podemos relatar ainda uma terceira situação em que se observou uma profissional do CAPS III realizando um atendimento clínico no NAC.

Estávamos no NAC, para realizar nossa supervisão de estágio. Encontrei XXXXXX, profissional do CAPS, em frente ao NAC. Chamou minha atenção ela estar ali. Ao encontrá-la novamente, disse que tinha ido fazer um atendimento à usuária YYYYY, que estava internada no NAC. Disse que tinha uma combinação com a usuária de fazer duas sessões semanais de psicoterapia, e que manteve esse atendimento neste outro serviço. Foi algo desestabilizador para mim, acostumado com o fato de cada profissional trabalhar em um único serviço da rede, sem vínculo com os demais. Será que a circulação dos profissionais entre os serviços não favorece o estabelecimento de uma atenção em rede? Como favorecer essa circulação? (Diário de Pesquisa).

Essa última situação aponta que o encaminhamento de um serviço para outro não necessariamente implica em quebra do vínculo entre usuário e terapeuta. Mesmo sendo encaminhada para outro serviço, a referência continua sendo um profissional do CAPS. Deve-se ressaltar que, no atual contexto da reforma psiquiátrica, a internação é vista como um recurso esporádico e de curta duração. Sendo assim, justifica-se a manutenção do vínculo com o profissional de referência do CAPS, pois após a alta hospitalar o usuário deve voltar a ser atendido no CAPS.

\section{Discussão}

O processo de regionalização dos CAPS está de acordo com a proposta do SUS e com a proposta preconizada pela Reforma Psiquiátrica (Brasil, 2004). Em relação aos CAPS de Campinas esse processo é ainda mais específico, pois cada CAPS atende uma região e cada equipe é referência para em média dois ou três Cen- tros de Saúde. A regionalização evita a duplicidade de recursos com a mesma finalidade, facilita o acesso aos serviços e o processo de referenciamento entre unidades de saúde.

A constituição das equipes de referência surge como uma alternativa à forma tradicional de organização dos processos de trabalho em saúde, marcadas pela lógica taylorizada, na qual existe uma dicotomia entre o planejamento e execução da ações, assim como um parcelamento e fragmentação do trabalho. Como expressão dessa lógica, Campos (1998) observou a composição de equipes nos serviços de saúde baseada segundo estratos profissionais: a equipe de enfermagem, o serviço de psicologia, o corpo médico. Nessa lógica, cada categoria conversa entre si, e, se necessário, conversa com a outra, tendo em vista uma hierarquia, ou ainda, em vez de conversarem entre si, encaminham o usuário de um profissional para outro ou de um serviço para outro através de uma guia de referenciamento. Como efeito desse sistema de organização dos processos de trabalho, observa-se a fragmentação do usuário segundo os recortes profissionais e institucionais, cabendo ao usuário agregar o que cada profissional prescreve. Como alternativa a esse modelo formulou-se a proposta de pensar as equipes como unidades de produção (Campos, 1998; Campos e Domitti; 2007; Campos e Amaral, 2007). Em vez de agrupar os trabalhadores em categorias profissionais homogêneas, agrupar diferentes categorias, constituindo o que observamos no SSCF como sendo as "equipes multiprofissionais de referência". Nessa perspectiva, os profissionais devem discutir entre si e agregar conhecimento uns em relação aos outros, de maneira que haja um compartilhamento de saberes e decisões entre eles. Há um duplo objetivo: propiciar a democratização das relações profissionais e uma atenção integral, não fragmentada em relação ao usuário. Observa-se, assim, a possibilidade de transversalizar os processos comunicacionais e de fluxo de usuários pela equipe e pelos serviços da rede assistencial.

Além da composição de equipes de referência, observa-se ainda a função dos "profissionais de referência”. Segundo Campos e Domitti (2007, p. 400):

a equipe ou profissional de referência são aqueles que têm a responsabilidade pela condução de um caso individual, familiar ou comunitário. Objetiva ampliar as possibilidades de construção de vínculos 
entre profissionais e usuários. 0 termo responsabilidade de condução refere-se à tarefa de encarregar-se da atenção ao longo do tempo, ou seja, de maneira longitudinal, à semelhança do preconizado para equipes de saúde da família na atenção básica.

Esse arranjo organizacional indica um importante papel de responsabilização das equipes e profissionais sobre os usuários. Designa ao mesmo tempo uma responsabilidade que é individual, mas também coletiva, pois o trabalhador está inserido em uma equipe, dentro do CAPS e dentro de um sistema de saúde, os quais podem (ou não) constituir condições de possibilidade para suas ações.

Tradicionalmente, um problema encontrado no campo da saúde mental são os encaminhamentos de um serviço a outro e as interferências desse mecanismo na clínica com pacientes em sofrimento psíquico grave (Campos, 2000; Alves e Guljor, 2004). No modelo tradicional de organização do processo de trabalho em saúde, baseado na lógica taylorizada, o encaminhamento deixa nas mãos do usuário a responsabilidade pelo acesso ao serviço ao qual é referenciado, cabendo ao profissional delimitar o que seu serviço pode ou não atender e qual o outro serviço mais adequado dentro da lógica hierarquizada do SUS. Nesse sentido, não entra em questão se o usuário tem condições de acessar o outro serviço (fator localização geográfica, condições financeiras); se o outro serviço tem disponibilidade de acesso ou é organizado por filas de espera; ou o sentido produzido no usuário em acessar outro serviço: abandono, esperança, ineficácia. Todos esses elementos passam a ser responsabilidade do usuário, e se ele não acessar o outro serviço ou houver uma fila de um ano de espera, o problema será considerado “daquele usuário” ou “daquele serviço”. Essa caricatura do mecanismo de referência e contrarreferência gera o que Alves e Guljor (2004) chamam de uma "assistência partida”. Outro risco é de que o fluxo do usuário seja guiado apenas pelo viés da doença e da sintomatologia, fazendo-o "perambular" verticalmente pela hierarquia “atenção básica-ambulatório-CAPS-internação". Essa é uma lógica ainda muito presente nos serviços de saúde, sendo que as equipes e profissionais de re- ferência surgem como novas respostas aos problemas daí decorrentes. No CAPS observado, uma das funções do técnico de referência é articular a atenção junto a outros lugares - sejam serviços de saúde, assistência social, trabalho -, traçar a linha do cuidado ${ }^{10}$ e buscar formas de ativá-la. Articular não implica apenas encaminhar o usuário de um lugar para outro. Também é relevante que o profissional possa manter contato com o local referenciado buscando conhecer suas formas de acesso, a disponibilidade para acolhimento, as contribuições ao projeto terapêutico do usuário. Outra característica do profissional de referência é que ele mantém essa função mesmo quando o usuário é referenciado para outro serviço, não havendo necessariamente uma quebra de vínculo entre usuário e terapeuta. É necessário ressaltar que essa continuidade é ainda mais relevante quando estamos lidando com usuários em sofrimento psíquico grave, em que existe uma perspectiva temporal tendencialmente longa em relação ao uso dos serviços de saúde.

Em relação às três situações relatadas (da reunião entre as equipes do CAPS e PSF; entre as equipes do CAPS e NAC; e do atendimento realizado por uma profissional do CAPS no NAC), destacam-se alguns pontos em comum entre eles e a mudança que eles apontam em relação ao modo tradicional de pensar a articulação entre os serviços. Em primeiro lugar, em vez do encaminhamento do usuário de um ponto a outro da rede, ocorre também um deslocamento dos profissionais, com o estabelecimento de parcerias e ações conjuntas. Em vez de uma equipe delegar a outra uma função, ocorre um compartilhamento de responsabilidades.

As parcerias com a rede básica são imprescindíveis, visto que, normalmente, os Centros de Saúde estão fisicamente mais próximos da residência do usuário. Além disso, muitos usuários manifestam uma adesão importante aos Centros de Saúde, ou por serem tratados neles durante anos, ou por pertencerem à mesma comunidade dos agentes comunitários de saúde. A proximidade física e subjetiva são instrumentos facilitadores para os processos de inserção social e intervenções domiciliares (Merhy e Amaral, 2007, p. 287).

10 Linha do cuidado é um termo trabalhado por autores como Ceccim e Ferla (2006) e Franco e Magalhães (2004). Associa-se à ideia de dar continuidade e agilidade ao fluxo de usuários pelos serviços e ações em saúde, através da desburocratização do acesso aos serviços e planejamento de ações coordenadas. 
O deslocamento dos profissionais entre os serviços, seja para a discussão de casos compartilhados, reuniões, realização de atendimentos, indica uma nova relação com o espaço interinstitucional. Apesar de os profissionais serem vinculados a um ou outro serviço, há possibilidades de circulação entre eles, a fim de atingir o objetivo que é a produção de saúde. Apesar do vínculo de trabalho com um serviço ou outro, o espaço potencial de atuação é a rede assistencial e social. Podese falar aqui de "nomadização" do espaço de trabalho, recorrendo ao pensamento de Deleuze e Guattari (1997) sobre o nomadismo. Segundo esses autores, nomadizar não implica necessariamente deixar de habitar um território. 0 nômade muda de lugar justamente para continuar habitando o território. Ele se desloca em busca das condições que lhe possibilitam viver, e na falta dessas condições ele muda de lugar. A partir dessa contribuição da filosofia da diferença, pensa-se na possibilidade de que não apenas os usuários se desloquem entre os serviços da rede, mas também os profissionais. Entende-se que, quando a profissional do CAPS vai fazer um atendimento no NAC, nomadizando seu espaço de trabalho, ela está indo atrás de condições que propiciam um encontro com o usuário, visando à produção de saúde. É uma forma de driblar um problema apontado por Campos (2000): a tendência de que o usuário portador de sofrimento psíquico, ao entrar em crise, seja encaminhado para outro serviço, sendo destituído de seus vínculos de confiança. No momento mais crítico, o usuário é mandado para outro lugar, onde tanto o local quanto as pessoas lhe são estranhas. Nesse sentido, o profissional de referência surge como possibilidade de intermediar e dar continuidade a esse processo.

É necessário apontar, no entanto, que o mero deslocamento espacial dos profissionais não resolverá todos os problemas, mas sim que esse deslocamento pode constituir-se em um dispositivo, um disparador de processos implicados com a produção da saúde, vida e sociabilidade. Para que essa possibilidade se atualize, são necessárias tanto condições materiais (meios de deslocamento da equipe) quanto afetivas (disposição de fazer esse trabalho). Além disso, aponta-se ainda a necessidade de um deslocamento intensivo - relativo ao paradigma que atravessa a intervenção - em que o objetivo deixa de ser a tutela e olhar sobre a doença mental e passa a ser a produção de saúde e o olhar sobre o sujeito em sofrimento em relação ao seu contexto social. A função do profissional de referência incorpora muitas contribuições do acompanhamento terapêutico (AT) no sentido de não caber a ele fazer pelo usuário, mas sim com o usuário. Além disso, o espaço de atuação profissional é configurado na relação com o usuário, rede social e outros profissionais, não se restringindo ao espaço físico do serviço de saúde.

Por último, aponta-se a importância da constituição das diretrizes macropolíticas de regionalização dos serviços, equipes e profissionais de referência, no sentido de propiciar um "em comum" entre os serviços da rede assistencial, uma lógica que transversaliza toda a rede de serviços e tende a facilitar os processos de comunicação e estabelecimento de parcerias entre os serviços. No plano organizativo, os serviços compartilham modos de funcionar, o que possibilita afirmar a função do profissional de referência e das equipes de referência como dispositivos de integração das redes assistenciais. É necessário apontar que, assim como funcionam como dispositivos de integração da rede assistencial, existe sempre o risco de tornarem-se dispositivos de burocratização, cristalização e enrijecimento da rede. Portanto, não é a existência do dispositivo em si que garantirá seu efeito de articulação, mas sim as conexões estabelecidas por ele, sua articulação com o campo micropolítico.

Nesse sentido, observa-se os processos de atualização e singularização dessas diretrizes em nível micropolítico, em que a macropolítica adquire sentido, desejo de ser implementada e até mesmo recriada e flexibilizada. 0 objetivo é a produção de saúde, e estando a organização do processo de trabalho em desacordo com esse objetivo, outras formas de organização são buscadas. Trata-se então de tomar essas diretrizes como normas passíveis de serem renormatizadas. Em vez de tomar a norma como cristalizada, ser capaz de recriá-la, potencializando o caráter normativo da instituição. Entende-se a ideia de "normatividade" tal qual proposta por Canguilhem (2005), que critica o entendimento da norma na perspectiva estatística (enquanto média padrão e desvio). Partindo da ideia de que a vida é instável e que a norma só é estabelecida em relação a um determinado meio, o autor coloca a necessidade de entender a saúde como a capacidade de estabelecer novas normas, de ser normativa, tendo em vista que nossa relação com o meio é sempre instável. 
Da mesma forma, entende-se que os serviços de saúde também são saudáveis na medida em que conseguem colocar em análise seus modos de funcionamento e produção de atos de saúde - suas "normas" - tendo a capacidade de renormatizá-las conforme as mudanças em relação ao meio.

\section{Considerações Finais}

Este artigo buscou tecer uma discussão sobre dispositivos de integração de uma rede assistencial em saúde mental, tendo em vista a experiência desenvolvida no início de 2005 no Serviço de Saúde Dr. Cândido Ferreira (SSCF), localizado no município de Campinas-SP.

A observação da experiência desenvolvida no SSCF permitiu concluir que tão importante quanto à implantação dos serviços substitutivos é pensar diferentes modos de articulação entre eles. Como destacamos, os dispositivos de articulação vão além da referência e contrarreferência tradicionalmente preconizada pelo SUS, compondo uma diversidade de tecnologias relacionais que implicam o compartilhamento de práticas e responsabilidade entre profissionais de diferentes serviços. Os processos de referenciamento não são vistos apenas dentro de uma ótica administrativa ou gerencial, mas também dentro de uma perspectiva relacional, visando garantir maior agilidade no acesso aos distintos níveis assistenciais, manutenção de vínculos entre profissional e usuário e entre profissionais de diferentes serviços. Ao mesmo tempo em que apresentamos um conjunto de serviços bastante diversificado e dispostos por regiões de saúde, apresentamos também as ações que tecem uma rede nas ações cotidianas dos trabalhadores dos serviços de saúde.

Destacamos a existência de um nível organizativo - macropolítico - em que os "profissionais de referência" e as "equipes de referência" comparecem como ferramentas de organização dos processos de trabalho e dispositivos de integração entre os serviços. Estes propiciam condições de possibilidade para o tecimento de articulações entre os serviços na medida em que delimitam responsabilidades e pressupõem a manutenção dos vínculos entre profissional e usuário. Apontamos, ainda, que o deslocamento dos profissionais por diferentes serviços, as reuniões e os planejamentos interequipes também podem constituir-se em dispositivos de integração da rede assistencial, propiciando um compartilhamento de responsabilidades.
O nível macropolítico só se efetivará estando articulado com o nível micropolítico, que consiste na atualização e singularização dos processos de trabalho no cotidiano, em que são estabelecidas novas relações com os espaços de produção de saúde - espaços nômades. Se em nível macropolítico o espaço é vislumbrado em uma perspectiva territorial-espacial, no nível micropolítico ganha relevância o aspecto relacional, dos contatos intermediados pelos trabalhadores.

Constata-se, assim, que os dispositivos de integração da rede assistencial em saúde mental devem ser formulados levando-se em consideração a convergência e complementaridade entre os planos macro e a micropolíticos, não podendo estes serem vistos como planos dicotômicos. As diretrizes macropolíticas não podem ser vistas como imposições, devendo sempre passar por processos de negociação e reformulação a partir da experiência micropolítica.

\section{Agradecimentos}

À prof. Dra. Claudia M. Perrone, pela leitura e discussão da primeira versão deste artigo. À Psicóloga Heloísa Amaral, Coordenadora de Ensino do SSCF, pela leitura do artigo e discussão deste artigo. Ao SSCF e seus profissionais pela disponibilidade para receber estagiários/pesquisadores e possibilitar uma formação em consonância com os princípios da Reforma Psiquiátrica. Aos demais alunos que participaram do estágio: Alexandra Ximendes, Carolina Schumacher, Michele Cervo, Michele Rezende, Sabrina Machado.

\section{Referências}

ALVES, D. S.; GULJOR, A. P. O cuidado em saúde mental. In: PINHEIRO, R.; MATTOS, R. A. de. (Org.). Cuidado: as fronteiras da integralidade. Rio de Janeiro: Hucitec: Abrasco, 2004. p. 221-240.

AMARANTE, P. D. C. O homem e a serpente: outras histórias para a loucura e a psiquiatria. Rio de Janeiro: Fiocruz, 1996.

BARROS, R. B. Reforma psiquiátrica brasileira: resistências e capturas em tempos neoliberais. In: CONSELHO FEDERAL DE PSICOLOGIA (Org.). Loucura, ética e política: escritos militantes. São Paulo: Casa do Psicólogo, 2003. p. 196-206. 
BRASIL. Ministério da Saúde. Saúde mental no SUS: os Centros de Atenção Psicossocial. Brasília, DF, 2004 .

CAMPOS, F. C. B. O modelo da reforma psiquiátrica brasileira e as modelagens de São Paulo, Campinas e Santos. 200o. Tese (Doutorado em Saúde Coletiva) - Unicamp, Campinas, 2000.

CAMPOS, G. W. S. O anti-taylor: sobre a invenção de um método para co-governar instituições de saúde produzindo liberdade e compromisso. Cadernos de Saúde Pública, Rio de Janeiro, v. 14, n. 4, p. 863-87o, 1998.

CAMPOS, G. W. S.; AMARAL, M. A. A clínica ampliada e compartilhada, a gestão democrática e redes de atenção como referenciais teórico-operacionais para a reforma do hospital. Ciência e Saúde Coletiva, v. 12, n. 4, p. 849-859, 2007.

CAMPOS, G. W. S.; DOMITTI, A. C. Apoio matricial e equipe de referência: uma metodologia para a gestão do trabalho interdisciplinar em saúde. Cadernos de Saúde Pública, Rio de Janeiro, v. 23, n. 2, p. 399-407, 2007.

CANGUILHEM, G. A saúde: conceito vulgar e questão filosófica. In: Escritos sobre a medicina. Rio de Janeiro: Forense Universitária, 2005. p. 35-48.

CECCIM, R. B.; FERLA, A. A. Linha de cuidado: a imagem da mandala na gestão em rede de práticas cuidadoras para uma outra educação dos profissionais de saúde. In: PINHEIRO, R.; MATTOS, R. A. (Org.). Gestão em redes: práticas de avaliação, formação e participação na saúde. Rio de Janeiro: IMS, UERJ, 2006. p. 165-184.
DELEUZE, G.; GUATTARI, F. Mil platôs: capitalismo e esquizofrenia. São Paulo: Ed. 34, 1997. v. 5.

FOUCAULT, M. História da sexualidade I: a vontade de saber. 17. ed. São Paulo: Graal, 2006.

FRANCO, T. B.; MAGALHÃES JR, H. M. Integralidade na assistência à saúde: a organização das linhas do cuidado. In: MERHY, E. E. et al. (Org.). O trabalho em saúde: olhando e experienciando o SUS no cotidiano. 2. ed. São Paulo: Hucitec, 2004. p. 125-135.

HARARI, A.; VALENTINI, W. (Org.). A reforma psiquiátrica no cotidiano. São Paulo: Hucitec, 2001.

LANCETTI, A. Clínica peripatética. São Paulo: Hucitec, 2006.

LATOUR, B. A esperança de pandora: ensaios sobre a realidade dos estudos científicos. Bauru: EDUSC, 2001.

MERHY, E. E. Saúde: a cartografia do trabalho vivo em ato. São Paulo: Hucitec, 2002.

MERHY, E. E.; AMARAL, H. (Org.). A reforma psiquiátrica no cotidiano II. São Paulo: Aderaldo \& Rothschild; Campinas: SSCF, 2007.

ONOCKO, R.; AMARAL, M. Cândido Ferreira: experimentando uma mudança institucional. In: MERHY, E. E.; ONOCKO, R. (Org.). Agir em saúde: um desafio para o público. 2. ed. São Paulo: Hucitec, 1997. p. 353-371.

ZAMBENEDETTI, G.; PERRONE, C. M. O processo de construção de uma rede de atenção em saúde mental: desafios e potencialidades no processo de Reforma Psiquiátrica. Physis: Revista de Saúde Coletiva, Rio de Janeiro, v. 18, n. 2, p. 277-293, 2008. 